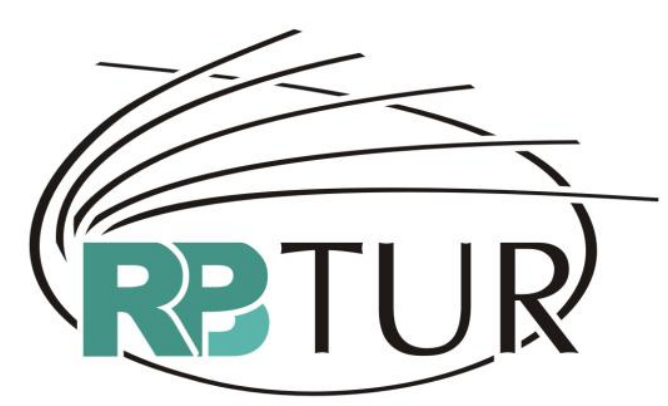

REVISTA BRASILEIRA DE PESQUISA EM TURISMO

\title{
CAPACIDADE DE CARGA EM CIDADES HISTÓRICAS
}

\author{
CARRYING CAPACITY IN HISTORIC CITIES
}

\section{CAPACIDAD DE CARGA EN CIUDADES HISTÓRICAS}

Fernando Vicente de Oliveira ${ }^{1}$

\begin{abstract}
Resumo: Neste artigo são apresentados os conceitos de capacidade de carga e capacidade ambiental vinculando-os ao manejo de cidades históricas dentro dos pressupostos do turismo sustentável. A avaliação da capacidade ambiental é uma valiosa ferramenta para planejamento turístico. O principal é determinar até que ponto um meio ambiente pode suportar uma intervenção, sem que a mesma danifique ou prejudique a característica principal deste local. As cidades históricas e turísticas com desejo de fomentar o turismo devem, necessariamente, delimitar suas capacidades de crescimento, para geração de riquezas através de sua economia diversificada e, sobretudo, bem estar de sua população, principal objetivo do estudo de capacidade ambiental.
\end{abstract}

Palavras chave: Turismo cultural. Cidades históricas. Capacidade de carga. Conceito e manejo.

Abstract: The article introduces the concepts of carrying capacity and environmental capacity referred to the management of historic cities on a sustainable basis. Environmental capacity assessment is a valuable tool for tourism planning. The issue is to determine how much intervention an environment can support without damage or harm to its characteristic features. Historic Cities and Tourist Cities willing to promote tourism have to be aware of the limits of its carrying capacities, diversifying economy and above all aiming to the locals wellbeing, which is the main scope of studies in environmental capacity.

Keywords: Cultural Tourism. Historic Cities. Carrying Capacity. Concept and planning.

Resumen: El artículo trata de los conceptos de capacidad de carga y capacidad ambiental vinculándolos a la gestión de ciudades históricas dentro de los pre-

${ }^{1}$ Arquiteto e Urbanista. Mestre em Social and Environmental Studies (Estudos Sociais e de Meio Ambiente) pela Universidade de Liverpool, Inglaterra. Mestre em Planejamento Urbano pela Pontifícia Universidade Católica de Campinas. Arquiteto responsável pelo planejamento urbano na Prefeitura da Estância Turística de Itu/SP. Professor de Estudos Ambientais Universidade Paulista. Email: fervioli@bol.com.br 
supuestos del turismo sostenible. La evaluación de la capacidad ambiental es una valiosa herramienta para la planificación turística. Lo principal es determinar hasta que punto un ambiente puede soportar intervención sin que esta lo dañe o perjudique sus principales características. Las ciudades históricas y turísticas interesadas en fomentar el turismo deben, necesariamente, delimitar su capacidad de crecimiento, generar riqueza mediante una economía diversificada y sobre todo pensar el bienestar de la población, que es el principal objetivo de los estudios de capacidad ambiental.

Palabras clave: Turismo Cultural. Ciudades Históricas. Capacidad de Carga. Concepto y planificación urbana.

\section{Introdução}

São cada vez mais pertinentes as preocupações locais e globais com a qualidade do meio ambiente. As relações entre a atividade turística e o meio ambiente, seus impactos e efeitos no patrimônio natural e construído, assim como na sociedade, determinam a prosperidade da atividade turística e seu desenvolvimento sem danos.

O planejamento turístico deve ser direcionado de uma maneira ambientalista, assegurando que a sociedade garanta sua sobrevivência sem exceder a capacidade de seu meio ambiente, pois é deste que provêem os recursos e o contexto para a economia e o desenvolvimento social. Sua proteção e sua melhoria devem ser os principais objetivos de qualquer política de planejamento.

Dentro deste princípio surge o conceito de capacidade ambiental, que tem suas raízes nas ciências naturais, mais especificamente na ecologia e no conceito de capacidade de carga. No campo do planejamento e do uso do solo, capacidade ambiental é, principalmente, um termo da década de 1990 . O meio ambiente tem um limite de tolerância à atividade humana, a partir da qual, se ultrapassada, passa a sofrer danos. O termo sustentável é usado, então, para expressar a idéia de que a sociedade humana precisa viver dentro dos limites determinados pela natureza, sem prejuízo deste meio ambiente. No contexto do planejamento, significa dizer que o desenvolvimento deve ser direcionado a não exceder a capacidade do meio ambiente para não esgotá-lo ou destruí-lo.

O termo capacidade de carga pode ser entendido como um sinônimo da capacidade ambiental. Na ecologia se refere ao tamanho de uma população de 
uma determinada espécie, que pode se sustentar indefinidamente em um hábitat. Quando se trata de gerenciamento urbano, capacidade de carga é usado para definir a extensão em que o meio ambiente pode tolerar a atividade humana sem sofrer danos inaceitáveis ou irreversíveis.

Essa definição é semelhante à capacidade ambiental. O que a distingue é que o termo capacidade ambiental considera a interação entre o meio ambiente e as atividades humanas em diferentes escalas, simultaneamente. Já o termo capacidade de carga é mais apropriadamente usado quando somente um aspecto do meio ambiente ou de uma atividade está sendo considerado, ou seja, quando se investiga como um determinado aspecto causa impacto em um meio ambiente específico, não se considerando o conjunto de ações.

A atividade econômica, por exemplo, gera produtos descartáveis que acabam se destinado aos aterros, atmosfera ou água. No entanto, há limites na tolerância aos excessos, pois o meio ambiente faz mais do que simplesmente assimilar os gastos provocados pelo homem e prover os recursos naturais para sua sobrevivência. Ele dá o suporte da vida, regula o clima, protege a Terra da radiação solar e mantém a biodiversidade de espécies animais e vegetais.

Entretanto não é apenas o meio ambiente natural que precisa ser protegido, mas também o que é feito pelo homem, o que chamamos de ambiente construído, o qual provê para a sociedade bens culturais e benefícios que vão desde uma bela paisagem até um local aprazível para viver e trabalhar. A importância disso não deve ser subestimada. Os benefícios resultantes de ar puro, água limpa e espaços verdes, particularmente em cidades, são vitais, assim como a configuração urbana que facilita a locomoção, moradia, trabalho e identidade de seus moradores.

\section{CIDADES HISTÓRICAS E DESENVOLVIMENTO TURÍSTICO}

Toda atividade humana produz história. No entanto, apenas alguns locais contêm uma densidade de documentos que despertam o interesse de 
visitantes. É o que normalmente se designa por sítios históricos. São muito diversos os parâmetros utilizados no mundo para considerar determinados edifícios, conjuntos edificados, cidades ou áreas como de valor histórico. Na Inglaterra considera-se histórica uma cidade que apresenta os seguintes elementos:

- uma malha urbana concentrada ou com padrões de rua distinto;

- domínio por um ou mais marcos históricos;

- uma mistura de usos e tipos de edifícios dentro da área histórica;

- uma localização física distinta que reflete suas origens (proximidade de um rio, ou quando este a cruza, posição defensiva, morro ou montanha, costa marítima etc.); e

- um entorno de desenvolvimento - além da malha central - que dá uma sensação de cidade economicamente ativa e não apenas histórica.

Essas características físicas não apenas fazem a historicidade do local visualmente atraente, mas também traçam o limite para o desenvolvimento futuro. Toda a área urbana deve ser considerada e não apenas alguns edifícios. Proteção e conservação enfrentam, assim, os interesses públicos e de autoridades locais, cuja atenção é freqüentemente voltada para o desenvolvimento econômico e/ou imobiliário, algumas vezes se sobrepondo ao desenvolvimento turístico.

\section{Questões de Planejamento para Cidades Históricas}

O problema fundamental que o planejamento enfrenta em cidades históricas é a tensão entre a necessidade de se conservar a malha física da cidade (seu centro e sua paisagem) e a demanda das atividades que ocorrem nesses espaços ou as que para ele são atraídas. Todos os problemas, em particular nas cidades históricas, originam-se desta tensão básica.

A idéia principal deve estar centralizada em preservar a malha histórica e prover os meios para os residentes e visitantes se beneficiarem de sua conservação. A cidade histórica, então, precisa funcionar como: 
- um "shopping center", ou seja uma área para o comércio e serviços locais;

- um centro para lazer e cultura;

- um local provido de instalações educacionais; e

- um lugar para se viver e trabalhar.

Estas atividades precisam ser acomodadas sem se danificar a malha ou o caráter da cidade, elementos que a tornam atraente. Uma destas tensões a ser enfrentada é o congestionamento de tráfego, com as ruas cheias de pedestres, pois visitantes e residentes têm que compartilhar o centro da cidade para compras e demais serviços. O planejamento deve selecionar como e onde as diversas atividades devem ser acomodadas.

Estas decisões tornam-se bem mais difíceis no contexto de uma cidade histórica. A cidade é atraente para um grande número de atividades; porém, ao mesmo tempo, há limites e problemas em virtude de seu caráter histórico e sua malha urbana inalterável, sendo que às vezes isso pode se tornar uma barreira para o desenvolvimento e adaptação a uma nova realidade.

\section{Turismo em Cidades Históricas}

Pode-se observar que, para valorizar suas áreas históricas, as cidades procuram atrair novas atividades e uma delas é o turismo associado a atividades culturais. O Turismo é usado para combater a imagem de uma cidade obsoleta, introduzindo novos usos que, desta maneira, tirem proveito de seu caráter histórico e do seu ambiente.

A consideração do Turismo como uma atividade apropriada para áreas internas das cidades é relativamente recente. A razão principal para fomentálo é a geração de uma nova forma de atividade econômica e empregos. Porém, o desenvolvimento do Turismo e de atividades culturais é mais do que simplesmente um componente de política econômica local.

O Turismo tem sido visto como uma crescente atividade, em parte devido ao aumento do tempo de lazer, assim como a facilidade de mobilidade em viagens. No desenvolvimento da atividade turística, em qualquer local, 
muitos fatores devem induzir o setor público a habilitar este desenvolvimento turístico dentro de suas áreas urbanas históricas. Isto inclui as razões econômicas, sociais e ambientais. Já o setor privado deve ser encorajado para o crescimento econômico. Do ponto de vista social, aumenta o orgulho local e o sentimento de bem-estar.

Planejar, então, torna-se essencial para gerir valores históricos com potencial turístico. No mundo pós-industrial, as cidades têm buscado promover atividades novas para substituir aquelas que acabaram-se no passado. Algumas cidades herdaram um melhor patrimônio, outras possuem recursos melhores, são melhor localizadas ou têm locais de maior potencial a serem explorados. Estas cidades precisam contar com atrações turísticas reconhecidas, diversificadas e infra-estrutura apropriada para que o turismo se estabeleça como efetiva atividade econômica.

As atrações podem incluir locais com facilidades para conferências, convenções e instalações para exibições e feiras de artes, museus, atividades de lazer e eventos especiais. Para representar um papel principal na revitalização, as instalações existentes devem ser melhoradas e assim somarem-se às novas atrações, observando-se os visitantes, seu comportamento e suas expectativas. Isto inclui a infra-estrutura de apoio que ajuda a aumentar o número de atrações, fomentando um processo de atração de visitantes, e requerendo o aumento de áreas de comércio, acomodações adequadas, mais transportes, agências de turismo e melhorias ambientais.

O Turismo, então, é mais que um componente de política econômica, desde que atraia investimentos e traga outros benefícios para a comunidade local como instalações, atrações e melhorias ambientais, tornadas economicamente viáveis pela presença do turista. A maioria dos turistas que chega às cidades busca visitar as suas principais atrações.

A variedade de instalações para os visitantes, as diversas atrações das cidades, sua herança cultural e os diversos tipos de lazer e recreação, oferecem as mais diversas experiências aos visitantes. Os conceitos de 
herança cultural e cidade histórica são importantes no entendimento do turismo e suas funções.

Muitos conflitos podem surgir como resultado desta convivência espacial do turismo com o meio ambiente histórico e natural. O dano físico, intencional ou não, pode ser o resultado de um excesso de visitantes que procura desfrutar da herança patrimonial da cidade.

Conservar o passado requer instalações de apoio modernas. As atrações podem ser coloniais, mas alguns turistas não estão preparados para dormir, comer ou viajar nas condições de épocas passadas. Por outro lado, o arrojado e moderno hotel pode se tornar um elemento intruso na paisagem histórica que os visitantes vieram desfrutar.

O Turismo tem impactos positivos como geração de renda, trabalho e impostos. Porém recentemente, ecologistas, cientistas sociais e até mesmo fomentadores de turismo, começam a levantar questões sobre a erosão dos recursos naturais, congestionamento e conflito social. De outro lado, o turismo pode desenvolver a paisagem visualmente e esteticamente. Arquitetos e outros profissionais têm feito parques, hotéis, "resorts"', áreas de recreação, parques temáticos e estradas mais agradáveis e funcionais para se tornarem também uma atração turística. Algumas ciências como economia, sociologia, geografia e ecologia estão dedicando uma atenção especial ao turismo que está produzindo um novo meio ambiente para uso próprio.

Ao mesmo tempo que alguns ambientes turísticos vêm sendo ampliados, admite-se que o turismo pode causar impactos ambientais negativos como poluição, congestionamento de pessoas e veículos. Um dos aspectos mais sérios do turismo de massa é o desgaste dos sítios históricos e dos edifícios. A pátina de envelhecimento nos edifícios históricos europeus por exemplo, é essencial para o visitante entender a imagem histórica da cidade. A super provisão de instalações para turistas também pode destruir esta 'imagem'.

\section{Possibilidades de Desenvolvimento}


Há preocupações ambientais muito significativas que interessam à cidade histórica turística, em particular os problemas com tráfego, congestionamento e poluição, que a curto ou médio prazo, causam danos por terem ultrapassado a capacidade ambiental. Assim, definições do termo foram citadas em "The Application of Environment Capacity to Land Use Planning" (DEPARTMENT OF THE ENVIRONMENT AND TRANSPORT AND REGIONS, 1997) e pode se destacar:

Capacidade ambiental é o ponto no qual os atributos especiais de uma cidade histórica começam a ser danificados através do crescimento, tanto diretamente no espaço, pelo desenvolvimento de seus limites urbanos, tanto pela pressão da atividade gerada pelo desenvolvimento deste espaço (ARUP et al., 1994).

O meio ambiente provê recursos para a sociedade e para a economia, mas há limites em que extensão isto pode ocorrer sem causar danos intoleráveis para o ecossistema e para a qualidade de vida. Desta maneira , o planejamento passa a discutir sobre as capacidades do meio ambiente (JACOBS, 1993).

O debate em torno de sustentabilidade originalmente enfoca o âmbito dos recursos naturais, mas há alguns princípios básicos que são úteis em termos de recursos feitos pelo homem. Trata-se de observar a capacidade do ambiente em aceitar demandas sem que sejam irreversíveis ou inaceitáveis para a integridade desse mesmo ambiente. Mudança irreversível em relação a uma cidade histórica seria o resultado da perda ou dano considerável nos elementos significativos de seu conjunto. Mudança inaceitável em relação a uma cidade histórica seria quando já não se mantém as características especiais que a fazem atraente (Formulações do "Environment White Paper", 1990, Reino Unido).

Um princípio básico de desenvolvimento sustentável está baseado em um conceito da economia de que há um recurso capital crítico, o qual não deve ser reduzido caso o investidor queira mantê-lo. Em termos de recursos naturais, o 'capital crítico' incluiria aquele que deva ser mantido para gerações futuras 
como os habitats protegidos e locais de especial interesse científico por exemplo. Para o estudo de cidades históricas ambos os recursos, naturais e construídos são importantes.

Os recursos que são críticos para a malha urbana ou para o caráter da cidade e em relação aos quais proteção e manutenção são preocupação primordial (capital ambiental crítico) incluiriam sítios arqueológicos ou históricos, edifícios listados e áreas designadas (áreas de conservação, áreas de paisagem privilegiada). São locais onde a preservação é fundamental, por serem insubstituíveis.

Há, em seguida, os recursos que contribuem para a malha urbana em um sentido geral ou também para o caráter da cidade, mas que são menos importantes, podendo até serem compensados em outros locais. Estes incluiriam subúrbios e os espaços abertos ao redor do centro que ajudam a configurar a cidade e seu caráter e onde a eliminação de uma determinada área pode ser compensada em outro lugar sem se perder o caráter global ou a qualidade da cidade.

Torna-se necessário então, identificar esses recursos que são críticos, ou seja, são os que formam o caráter global e dão qualidade à cidade. Pode-se assim expandir a capacidade ambiental de um local através de sua adequada gestão ou da criação de alternativas para se utilizar outros que a cidade tem a oferecer.

O desenvolvimento turístico-histórico oferece um potencial ambiental muito positivo. O turismo de herança cultural tem papel importante na justificativa da conservação, formando opiniões a favor de se manter os lugares históricos. Por outro lado, há um preço a ser pago quando se usa esses lugares como único recurso para atrair o turismo, pois seu excesso pode danificar a malha histórica. Também, a superdependência do turismo pode gerar problemas de administração no restante da cidade histórica.

\section{APLICABILIDADE DO CONCEITO DE CAPACIDADE AMBIENTAL EM CIDADES HISTÓRICAS}


A natureza, assim como a cidade, são elementos com potencial turístico, mas enquanto a primeira não pode ser ampliada, a cidade desenvolve-se e cresce. A própria existência da natureza já constitui a sua atratividade. $\mathrm{Na}$ cidade histórica, os edifícios, prédios e monumentos com significado artístico e histórico, constituem a atratividade, e a diferenciam das demais cidades.

Temos que é muito complexo a operacionalização e a determinação da capacidade de carga de uma cidade ou um local turístico. Há vários componentes que determinam a qualidade do local: a temperatura, o índice pluviométrico, fauna e flora, estado dos edifícios e monumentos etc.. Também é importante se determinar a tipologia da freqüência e as modalidades da intervenção sobre o espaço (semanal, sazonal ou permanente) e do tipo de lazer praticado (passeios, turismo educativo, esportivo, familiar, jovem etc.). 0 comportamento dos indivíduos também é um determinante pois muitas vezes se apresenta inadequado, inaceitável mesmo, uma vez que estão fora do seu meio cultural. Em resumo, as maiores dificuldades estão na determinação da quantidade ideal de turistas e sua distribuição no tempo e no espaço, dos meios disponíveis para conter excessos, e na escolha de modelos de desenvolvimento a implantar.

O desenvolvimento do turismo em cidades históricas, que com sua beleza própria exercem grande um magnetismo, pode provocar um excesso de demanda e superdimensionamento de oferta, agredindo e descaracterizando o meio ambiente.

Como isto vem ocorrendo com freqüência e velocidade acentuadas, tem chamado a atenção de grupos que estão envolvidos na questão. Em cada cidade ou localidade há uma subjetividade de critérios que passam a direcionar decisões quanto ao que deve e pode ser feito de maneira que atenda aos interesses das partes envolvidas. As crescentes ondas de turistas nacionais e estrangeiros constituem motivo de orgulho para alguns países, porque assim as metas quantitativas são alcançadas. 
A exagerada afluência de turistas em espaços naturais e construídos deve ser controlada, pois, além de certos limites, o excesso de visitantes pode anular as atrações que motivaram sua viagem, perturbando o equilíbrio do local. Desta maneira, para o gerenciamento e administração de atividades recreativas, o conceito de capacidade de carga foi desenvolvido para se estabelecer o limite de um determinado espaço.

Admitindo a possibilidade de aplicar esses conceitos de capacidade ambiental e capacidade de carga, advindos do estudo do meio natural, ao meio ambiente construído, de interesse turístico - cidades históricas, Arup (1994) e seu grupo de estudos desenvolveram extenso estudo, utilizando como referência a cidade de Chester (Reino Unido). Assim pode-se criar um modelo de capacidades para a cidade, como mostrado na Figura 1.

Nesse modelo os elementos assinalados com letras são assim explicitados:

- A - são os atributos físicos que fazem a cidade se tornar especial: a forma física e a malha urbana da cidade e edifícios, ruas, parques enfim, todas as construções e o meio ambiente natural.

- B - são as atividades da cidade em termos de trabalho, lazer, recreação e moradia.

- C - é o funcionamento dos sistemas existentes na cidade e a interação entre eles.

- D - são as funções que a cidade desempenha e uma análise de sua percepção.

Há uma interação entre estes quatro elementos, gerando tensões. $\mathrm{Na}$ análise destas tensões, questões relevantes quanto aos limites da cidade irão surgir. A cidade tem elementos-chave, ou seja, de importância relevante, e limites para o seu desenvolvimento. 


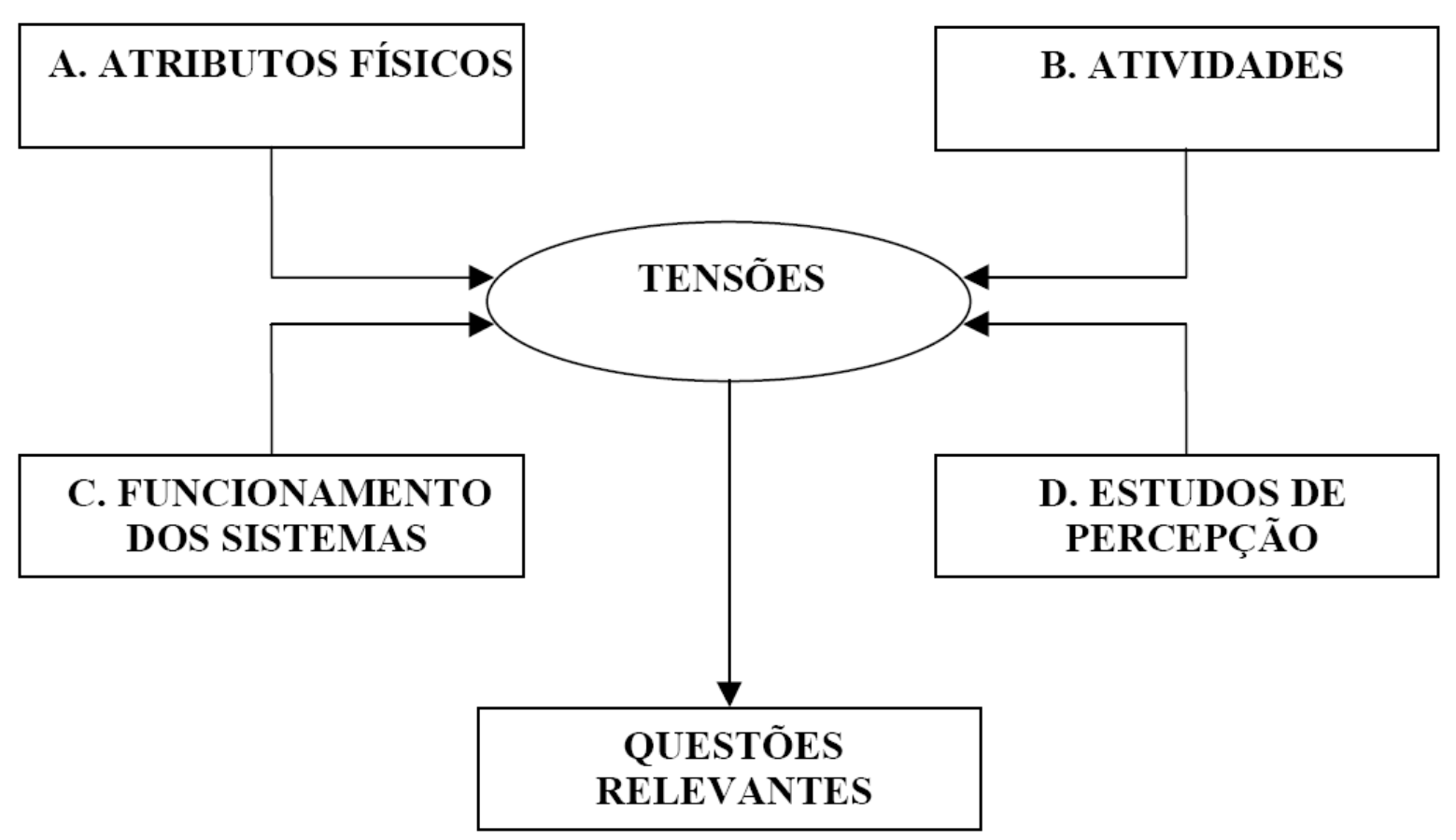

Figura 1 - Modelo para Estudo das Capacidades de uma Cidade Fonte: Arup et al., 1994

As questões surgem, portanto, dos estudos de capacidade ambiental que dão as informações necessárias para detectar os principais problemas e um bom quadro dos limites a serem respeitados. A sua determinação está relacionada somente com os atributos físicos de um lugar. O importante neste estudo é o contínuo monitoramento dos impactos e efeitos no meio ambiente, evitando-se desta maneira problemas futuros.

Constitui um trabalho onde não se pode prever o futuro, mas detectar as tensões que surgem decorrentes da atividade humana. As considerações sociais e econômicas não podem ser isoladas. Assim, deve ser considerado como uma importante ferramenta de informações para a elaboração de Planos de Desenvolvimento Turístico e Planos Diretores, mas não cabe esperar dele mais do que isso.

\section{CONCLUSÃO}

Os conceitos de capacidade ambiental e de capacidade de carga usados para o gerenciamento turístico são de fundamental importância para estimar 
os níveis em que os diferentes meios ambientes podem acomodar a atividade humana. Eles também dão o balanço entre a capacidade perceptual, de satisfação do visitante e a comunidade receptora, para atingir o equilíbrio desejado.

No campo natural ou ecológico, a sensibilidade é bem maior; assim, os critérios para intervenção nesses meios devem ser analisados por técnicos das áreas das ciências naturais, para sua melhor eficácia. No âmbito das cidades, particularmente as de valor histórico, a quantificação numérica torna-se complexa por conter mais variáveis de avaliação subjetiva. Há sem dúvida, a vontade, por parte das estâncias, de atrair visitantes para que ocorra maior desenvolvimento de sua economia.

Neste início de século, cidades em todo o mundo estão enfrentando problemas de fundamental importância que têm suas origens nas mudanças na economia e nas características sociais globais. Todos os governos enfrentam problemas. Algumas cidades, principalmente as históricas, acabam sendo deterioradas fisicamente e têm infra-estrutura precária. Isso cria uma imagem negativa do lugar, tanto para viver, trabalhar e visitar. O estudo de capacidade ambiental tem um caráter preventivo dentro de uma política protetora do meio ambiente. O patrimônio ambiental é um elemento essencial para o desenvolvimento turístico. Sua boa gestão envolve reconhecimento e o estabelecimento dos limites que não podem ser ultrapassados em nome de um desenvolvimento, o qual não seja sustentável.

O uso de modelos como de capacidade ambiental, já implantados em cidades européias, podem ser o ponto de partida, para a adoção de práticas para gestão de cidades e desenvolvimento de uma atividade turística. Com o comprometimento do debate aberto com a população local, órgãos públicos e visitantes, podemos discutir o quê se quer para as cidades, dentro de uma realidade dos limites físicos. Em uma sociedade globalizada, onde a lógica dominante é uma competitividade acirrada, muitas vezes injusta, deve-se ao menos, dimensionar estes limites físicos e sociais, para assim efetivar as ações. A construção de uma justiça social, de modelos sustentáveis de 
planejamento, depende de todos, articulados com planejadores urbanos e acadêmicos compromissados com uma sociedade justa, de equilíbrio e igualdade para todos.

\section{REFERÊNCIAS}

ARUP, Ove et al. Environmental capacity and development in historic cities. A study with special reference to Chester, methodology report. Chester. Cheshire County Council/Chester City Council/Department of the environment/English Heritage. 1994.

ASHWORTH, Gregory e GOODALL, Brian. Marketing in the tourism industry: The promotion of the destination regions. Londres. Croom Helm, 1990.

BARRETTO, Margarita. Planejamento e organização em turismo. Campinas. Papirus, 1996.

BENI, Mario Carlos. Análise estrutural do turismo. 3a. ed. São Paulo. Senac, 2000.

BOUD-BOVY, Manuel e LAWSON, Fred. Tourism and recreation development. Londres: The Architectural Press, 1977.

DE JONGE, D. Images of urban areas: Their structure of psychological foundations. Journal of the American Institute of Planners, 1962, vol 28.

DEPARTMENT OF THE ENVIRONMENT AND TRANSPORT AND REGIONS - DETR. The application of environmental capacity to land use planning. Londres: The Department. 1997.

DoE- DEPARTMENT OF THE ENVIRONMENT. New life for historic area. Londres: The Department. 1972.

- Planning policy guidance note 12. Development plans and regional planning guidance, HMSO. Inglaterra. The Department. 1992.

(1994). Quality in town and country. Great Britain: The Department.

ENVIRONMENT White Paper. "England: This common inheritance - Britain's environmental strategy", 1990.

FRANCESCATO, D. e MEBANE, W. How citizens view two great cities Milan and Rome. Image and the environment. Chicago: [s.n.], 1973.

GUNN, Clare A. Tourism Planning. [s.l.]: Taylor and Frances, 1988.

INSALL, Donald. Chester: $A$ study in conservation. Chester: Donald Insall \& Associates, 1973.

JACOBS, Michael Sense and Sustainability: Land use planning environmentally sustainable development. Londres: CPRE, 1993.

LARKHAM, Peter J. Conservation and the city: Routledge. Londres e Nova York [S.n.]. 1996.

LEMOS, Amália Inés G. Turismo: Impactos socioambientais. 2a ed. São Paulo: Hucitec, 1999.

LYNCH, Kevin. The Image of the city. MIT Press, 1960.

TIESDELL, Steven; TANER, C. e HEATH, Tim. Revitalising historic urban quarters. Londres: Architectural Press, 1996. 
OLIVEIRA, Fernando Vicente de. Capacidade de carga em cidades históricas. Revista Brasileira de Pesquisa em Turismo. v.4, n.1, p. 61-75, abr. 2010.

Artigo recebido em janeiro de 2010.

Aprovado para publicação em março de 2010. 